\title{
A topographic framework for estimating spatial variation in hill country grasslands
}

\author{
R.L. PHILLIPS ${ }^{1,2}$, M.R. EKEN ${ }^{2}$ and B.C. RUNDQUIST ${ }^{3}$ \\ ${ }^{1}$ Landcare Research, Gerald Street, Lincoln, New Zealand \\ ${ }^{2}$ Ecological Insights, $5016^{\text {th }}$ Ave NE, Mandan, ND 58554, USA \\ ${ }^{3}$ University of North Dakota, 3701 Campus Rd, Grand Forks, ND 58202, USA \\ phillipsr@landcareresearch.co.nz
}

\begin{abstract}
Livestock graze hill country regions worldwide where grassland biomass or structure is important both economically as forage and enviromentally as habitat for wildlife. Manual measurements of biomass in remote and expansive hill country landscapes are time consuming, expensive, and difficult to estimate due to spatiotemporal variability. Pasture areas where livestock utilisation or grassland biomass is exceptionally high or low could be mapped within a topographic framework. A model was developed that integrates several data sources (elevation, spectra and field data) to estimate hill-country biomass. Topographic data were modelled and used to classify biomass, which ranged from low at summits $(1493 \mathrm{~kg} / \mathrm{ha})$ to high at toe-slopes $(2876 \mathrm{~kg} / \mathrm{ha})$. These estimates were compared with the current plant height-based model, which ranged from low $(2014 \mathrm{~kg}$ / ha) to high (3032 kg/ha). This paper demonstrates how expansive, heterogeneous grassland landscapes can be assessed seasonally using topographic markers within an integrated spatial data framework.
\end{abstract}

Keywords: Remote sensing, DEM, structure, Landsat 8 , forage utilisation, graziers

\section{Key messages}

- Topographic and height-based indicators of grassland structure are comparable

- New model developed for the Unite States hill country is applicable to New Zealand

- Grazing can be finely tuned with low-cost, seasonal maps indicating utilisation.

\section{Introduction}

Hill country landscapes worldwide support multiple uses such as forage for livestock, wildlife habitat and recreational hunting. The need to collect and map grassland heterogeneity has been demonstrated by researchers in both the North and South Islands of New Zealand and other areas of the world (Radcliffe 1982; Schellberg et al. 2008; Vartha et al. 1982). However, data maps representing grassland total standing crop (TSC) or structure for these expansive hill country landscapes are currently not available. Intensification of agriculture in New Zealand has raised new questions about the capacity of hill country grasslands to sustainably produce more forage without compromising other ecosystem services, such as structure for wildlife cover. Data maps indicating the full range of spatial variation in grassland stocks across the landscape could indicate how livestock utilisation effects pasture production under variable climates. These technologies are available, but data costs and processing (acquisition, ortho-rectification, calibration, and analysis) expenses can be prohibitively high, particularly when data are collected on aerial or drone platforms. Low-cost, spatially explicit approaches for assessing locations where forage may be over- or under-utilised are needed as greater pressure is placed on hill country pastures to support the world demand for food production.

Field-based measures of canopy height (Sjursen 2009; Svingen 2009; Uresk \& Juntti 2008) and spectralbased measurements of canopy reflectance (Chen 1996; Washington-Allen et al. 2006) are common grassland assessment metrics. When height and TSC are highly correlated, the regression model is considered an estimate of grassland structure (Robel et al. 1969; Uresk \& Benzon 2007; Uresk \& Juntti 2008; Vermiere \& Gillen 2001; Vermiere et al. 2002). These regression models change with a number of factors, such as species composition (Phillips 2014). Practitioners rarely measure both height and TSC; both are commonly used as proxies for structure (Robel et al. 1969). Spectral data are often applied to estimate TSC, but spectral indices are also influenced by a number of factors, such as plant water content, species composition and soil background (Phillips et al. 2006). Hill country grasslands present a unique set of challenges for large-scale assessment mapping (Schellberg et al. 2008). Application of simple models or a spectral index cannot adequately represent expansive, heterogeneous hill country landscapes.

Spectral data acquired using sensors on-board aircraft and satellites can be modelled to estimate plant chemical and structural characteristics, and optimum models for estimating variables such as TSC or nitrogen content vary seasonally (Chen 1996; Phillips et al. 2012; Phillips et al. 2013; Washington-Allen et al. 2006). In many of these cases, aerial hyperspectral data are collected in conjunction with intensive field campaigns, and results indicate some plant canopy 
characteristics can be effectively mapped (Beeri et al. 2007; Haboudane et al. 2004; Phillips et al. 2012; Phillips et al. 2013; Pullanagari et al. 2013). Another approach, which provides a greater spatial extent at lower cost, is to correlate multispectral data acquired from satellite-based sensors with field data (Phillips et al. 2006; Phillips et al. 2012). Choices regarding the type of spectral data (multispectral or hyperspectral) and platform (satellite, aircraft, drone) affect the spatial coverage, cost and accuracy. The expansive nature and physiography of grasslands in hill country are particularly suited to application of satellite-based, spectral data when used in conjunction with topographic and field data (Phillips et al. 2012; Phillips et al. 2013; Phillips 2014). Additional work is needed to evaluate application of topographic position as a metric for defining low, medium and high TSC biomass relative to the current field metric of canopy height.

Here, we aimed to evaluate a hill-country assessment framework that applies known variation in topographic position (Phillips et al. 2012; Phillips et al. 2013; Radcliffe 1982) to classify thresholds in total standing crop biomass (TSC-Topo) relative to the current canopy height-biomass (TSC-Height) model. This case study was performed in the northern mixed-grass prairie region of the USA, where elevation changes and plant functional groups are comparable to New Zealand hill country regions (Dalton \& Ackerley 1974; Phillips et al. 2012; Phillips et al. 2013; Radcliffe 1982; Vartha et al. 1982). The goal was to evaluate total standing crop biomass according to: (1) the TSC-Height model (where low biomass is defined as height $<9 \mathrm{~cm}$ ); and (2) the TSC-Topo model (where low biomass is defined by summits). A comparison of these approaches would demonstrate (1) how field data could be modelled to provide a spatially explicit map of TSC biomass for expansive hill-country landscapes and (2) how extrapolation from field to landscape scales in heterogeneous grasslands is facilitated by spatial data integration.

\section{Methods}

The 30385 ha area-of-interest (AOI) used to develop and test this framework is located in northwestern South Dakota, USA. The AOI is comprised of multiple grazing allotments that are leased for grazing by the United States Forest Service from May to September each year. This landscape was classified into summit (4.4\%), mid-slope (61.1\%) and toe-slope (34.5\%) polygons (Phillips et al. 2012). Previously established plots within the AOI were re-visited for plant data collection in July and September 2014. These 24 plots were split into summit, mid-slope, and toe-slope positions. Each topographic position within a plot is referred to as a field site, with a total of 72 field sites. In July 2014, Daubenmire plots were used to identify the top five species at each site, based on data collected in four cardinal directions (Phillips et al. 2012). In September 2014, TSC biomass was determined with Daubenmire plots in four cardinal directions and plant height according to established procedures (Phillips et al. 2012; Phillips et al. 2013). Samples were separated into green and senescent vegetation, and then ovendried at $60{ }^{\circ} \mathrm{C}$. The relationship between TSC and plant height was determined to estimate TSC thresholds associated with low $(<9 \mathrm{~cm})$, medium-low $(9-12 \mathrm{~cm})$, medium-high $(12-18 \mathrm{~cm})$, and high $(>18 \mathrm{~cm})$ structure (Phillips et al. 2012).

All TSC data are reported on a dry matter basis $(\mathrm{kg} /$ ha). A cloud-free Landsat Operational Land Imager (OLI) image was acquired from the Landsat 8 platform on 14 September 2014. The image was downloaded from the Land Processes Distributed Active Archive center (http://glovis.usgs.gov). The raw radiometric

Table $1 \quad$ Spectral bands Landsat 8 (USGS 2014).

\begin{tabular}{lcccc}
\hline Band & Description & Symbol & Wavelength (nm) & Resolution (m) \\
\hline 1 & Coastal/Aerosol & $P C A$ & $430-450$ & 30 \\
2 & Blue & PBlue & $4450-510$ & 30 \\
3 & Green & PGreen & $4530-590$ & 30 \\
4 & Red & PRed & $4640-670$ & 30 \\
5 & Near-Infrared & PNIR & $4850-880$ & 30 \\
6 & Short-wave Infrared 1 & PSWIR1 & $41570-1650$ & 30 \\
7 & Short-wave Infrared 2 & PPan & $42110-2290$ & 30 \\
8 & Panchromatic & PCirrus & $4500-680$ & 15 \\
10 & Cirrus & STIR1 & $41360-1380$ & 30 \\
11 & Thermal Infrared Sensor 1 & STIR2 & $410600-11190$ & $100(30)^{\mathrm{a}}$ \\
\hline
\end{tabular}


data were corrected by applying date-specific instrument calibration parameter files, which converted 12-bit satellite-quantized digital numbers (DN) to atsensor radiance (USGS 2015). The image was clipped to the AOI containing the 72 field sites. Atmospheric correction to at-surface reflectance was performed in ENVI 5.3 (Exelis Inc., Tysons Corner, VA) using QUAC (QUick Atmospheric Correction). Pixel values at the 72 field sites were extracted for bands 2-7 (Table 1) and used to calculate spectral indices (Table 2).

Stepwise regression analysis was used (Phillips et al. 2013) to select the spectral index (Table 2) most predictive of TSC. The data were randomly partitioned into training (0.66) and test datasets (0.33), so the Root Mean Square Error (RMSE) could be reported based on the separate test or validation data set. Resulting equations were used to estimate TSC for each pixel in the AOI. Modelled TSC by pixel was averaged by polygon and mapped. The data were then classified into low, medium-low, medium-high, and high TSC biomass using (a) the linear relationship between TSC and canopy height at the 72 field sites (TSC-Height) and (b) average modelled TSC for summit, mid-slope and toeslope for the entire AOI (TSC-Topo). The proportion of the AOI in each class was calculated, based on each approach and used as a basis of comparison.

\section{Results}

\section{Field data}

Species data collected in July at the 72 field sites are given in Table 3. Summit plant cover was dominated by shortgrass species. Mid-slopes and toe-slopes, on the other hand, were dominated by mid-grass species and tall sweet clover (Melilotus officinalis). In September,

Table 2 Spectral vegetation indices tested in the fieldcalibrated model.

\begin{tabular}{|c|c|}
\hline Index & Equation \\
\hline NDVI & $\left(\rho_{N I R}-\rho_{R e d}\right) /\left(\rho_{N I R}+\rho_{R e d}\right)$ \\
\hline EVI & $2.5 *\left(\rho_{N I R}-\rho_{\text {Red }}\right) /\left(\rho_{N I R}+6 * \rho_{\text {Red }}-7.5 * \rho_{\text {Blue }}+1\right)$ \\
\hline SR71 & $\rho_{\text {SWIR } 1} / \rho_{\text {Blue }}$ \\
\hline ND53 & $\left(\rho_{\text {SWIR } 1}-\rho_{R e d}\right) /\left(\rho_{\text {SWIR } 1}+\rho_{R e d}\right)$ \\
\hline NDSVI & $\left(\rho_{\text {SWIR } 2}-\rho_{\text {Red }}\right) /\left(\rho_{\text {SWIR } 2}+\rho_{\text {Red }}\right)$ \\
\hline SWIR3/SWIR2 & $\rho_{\text {SWIR2 }} / \rho_{\text {SWIR } 1}$ \\
\hline MTVI1 & $1.2\left[1.2\left(\rho_{\text {NIR }}-\rho_{\text {Green }}\right)-2.5\left(\rho_{\text {Red }}-\rho_{\text {Green }}\right)\right]$ \\
\hline MTVI2 & $1.5\left[\frac{\left(1.2\left(\rho_{\text {NIR }}-\rho_{\text {Green }}\right)-2.5\left(\rho_{\text {Red }}-\rho_{\text {Green }}\right)\right)}{\left(\left(\sqrt{\left(2 * \rho_{\text {NIR }}+1\right)^{2}}\right)-\left(6 * \rho_{\text {NIR }}-5 * \sqrt{\rho_{\text {Red }}}-0.5\right)\right)}\right.$ \\
\hline NDWI & $\left(\rho_{S W I R 1}-\rho_{N I R}\right) /\left(\rho_{S W I R 1}+\rho_{N I R}\right)$ \\
\hline ND71 & $\left(\rho_{\text {SWIR } 2}-\rho_{\text {Blue }}\right) /\left(\rho_{\text {SWIR } 2}+\rho_{\text {Blue }}\right)$ \\
\hline SWIRDVI & $\left(\rho_{S W I R 2}-\rho_{S W I R 1}\right) /\left(\rho_{S W I R 2}+\rho_{S W I R 1}\right)$ \\
\hline SATVI & $\begin{array}{c}{\left[\left(\rho_{\text {SWIR } 2}-\rho_{\text {Red }}\right) /\left(\rho_{\text {SWIR } 2}+\rho_{\text {Red }}+0.5\right) * 1.5\right]} \\
-\left(\rho_{\text {SWIR } 2} / 2\right)\end{array}$ \\
\hline NDII & $\left(\rho_{S W I R 1}-\rho_{N I R}\right) /\left(\rho_{S W I R 1}+\rho_{N I R}\right)$ \\
\hline MSI & $\rho_{S W I R 2} / \rho_{N I R}$ \\
\hline
\end{tabular}

most of the vegetative material was senescent. Green material (photosynthetically active vegetation) ranged from 37 to $42 \%$ at all topographic positions. Average (std. error) canopy height for summit, mid-slope and toe-slope positions at the field sites were 7 (1) $\mathrm{cm}, 12$ (1) $\mathrm{cm}$, and $12(1) \mathrm{cm}$, respectively. Average TSC (both green and senescent vegetation) was 1195 (96), 2518 (212), and 3091 (273) kg/ha, at summit, mid-slope and toe-slope positions, respectively. Figure 1 and Equation 1 demonstrate the relationship between canopy height and TSC at the 72 field sites.

$$
\text { TSC }=484+170 * \text { height; } \mathrm{r}^{2}=0.61
$$

Plant height at 37 of the 72 field sites was $<9 \mathrm{~cm} ; 21$ of the 37 field sites below $9 \mathrm{~cm}$ were located at summits, as shown in Figure 1. The remaining 16 field sites below $9 \mathrm{~cm}$ were located at mid-slope and toe-slope positions. The TSC-height model (Figure 1; Equation 1) indicated low structure $(<9 \mathrm{~cm}$ height $)$ corresponded to TSC values $<2014 \mathrm{~kg} / \mathrm{ha}$. Medium-low structure (9$12 \mathrm{~cm}$ height) corresponded to TSC ranging from 2 014-2524 kg/ha; medium-high structure $(12-15 \mathrm{~cm})$ to TSC ranging from $2524-3034 \mathrm{~kg} / \mathrm{ha}$; high structure (> $15 \mathrm{~cm}$ ) to TSC $>3034 \mathrm{~kg} / \mathrm{ha}$.

\section{Modelled TSC}

The statistical model selected topographic position and the Modified Triangular Vegetation Index 1 (MTVI1) as the spectral index (Haboudane et al. 2004) most predictive of TSC. Equations for estimating TSC at each topographic position are given below.

$$
\begin{aligned}
& T S C_{\text {Summit }}=863+(0.87 * \text { MTVI1 })-982 \\
& T S C_{\text {Mid-slope }}=863+(0.87 * \text { MTVI1 }) \\
& T S C_{\text {Toe-slope }}=863+(0.87 * \text { MTVI1 })
\end{aligned}
$$

The RMSE for modelled TSC at all topographic positions, based on hold-out (test) samples, was 940 $\mathrm{kg} / \mathrm{ha}$.

Table 3 Dominant plant species observed at the 72 field sites July 2014.

\begin{tabular}{lcccc}
\hline $\begin{array}{l}\text { Functional } \\
\text { Group }\end{array}$ & Scientific Name & Summit & $\begin{array}{c}\text { Mid } \\
\text {-slope }\end{array}$ & $\begin{array}{c}\text { Toe } \\
\text {-slope }\end{array}$ \\
\hline Mid & Agropyron cristatum & & & $\mathrm{X}$ \\
Short & Bouteloua gracilis & $\mathrm{X}$ & & \\
Short & $\quad$ Carex sp. & $\mathrm{X}$ & $\mathrm{X}$ & \\
Mid & Hesperostipa comata & $\mathrm{X}$ & $\mathrm{X}$ & \\
Short & Koeleria macrantha & $\mathrm{X}$ & & \\
Forb & Melilotus officinalis & & $\mathrm{X}$ & $\mathrm{X}$ \\
Mid & Nassella viridula & & $\mathrm{X}$ & $\mathrm{X}$ \\
Mid & Pascopyrum smithii & $\mathrm{X}$ & $\mathrm{X}$ & $\mathrm{X}$ \\
Mid & Poa pratensis & & & $\mathrm{X}$ \\
\hline
\end{tabular}


Total Standing Crop vs. Canopy Height

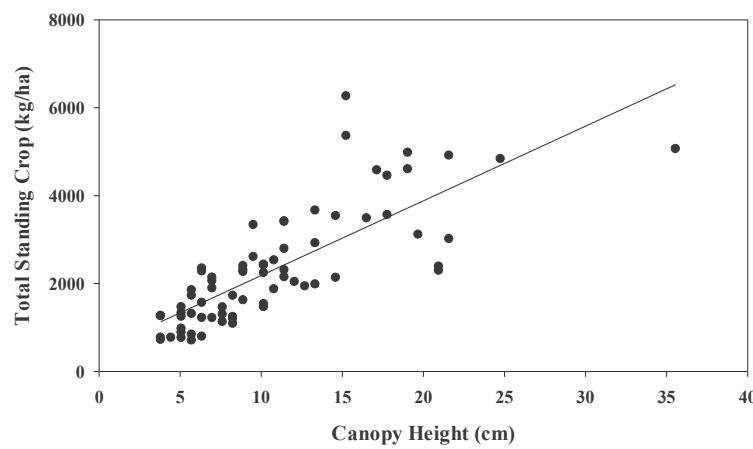

Figure 1 Regression of total standing crop (TSC) on canopy height measured at the 72 field sites 15 September 2014.

A comparison of measured and modelled TSC topographic position is depicted in Figure 2. The first and second bars at each topographic position in Figure 2 indicate TSC measured and modelled, respectively, at the 72 field sites. The third bar in Figure 2 indicates model-based TSC at summits, mid-slopes and toeslopes for the entire AOI. All three estimates of TSC indicated summit TSC were consistently lower than mid-slopes and toe-slopes. This result provided the basis upon which summit data could be used as indicators of low TSC. Field-site measured and modelled TSC by topographic position were more closely aligned than TSC estimated by topographic position for the entire AOI.

Trends in TSC by topographic position modelled for the entire landscape were similar to trends at the 72 field sites (Figure 2). The proportion of the landscape

Table 4 Grand River National Grassland percentage and hectares within each threshold group by modelling type.

\begin{tabular}{cccc}
\hline & \multicolumn{3}{c}{ TSC-Height Threshold } \\
\cline { 2 - 4 } Low & $\mathbf{c m}$ & ha & $\%$ \\
Med-Low & $<9$ & 1351 & 4.5 \\
Med-High & $9-12$ & 3316 & 10.9 \\
High & $12-15$ & 13921 & 45.8 \\
& $>15$ & 11797 & 38.8 \\
& \multicolumn{3}{c}{30385} \\
\cline { 2 - 4 } & $\mathbf{k g} / \mathbf{h a}$ & TSC-Topo Threshold \\
Low & $<1493$ & 832 & $\%$ \\
Med-Low & $1493-2487$ & 3141 & 10.3 \\
Med-High & $2487-2876$ & 11940 & 39.3 \\
High & $>2876$ & 14472 & 47.6 \\
& & 30385 & \\
\hline
\end{tabular}

Total Standing Crop by Topographic Position

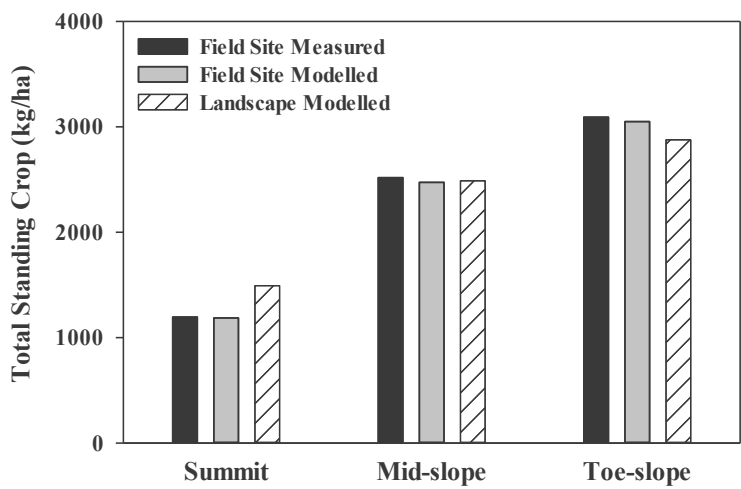

Figure 2 Average (std. error) total standing crop (TSC) measured and modelled at the 72 field sites by topographic position. The hatched bars represent average modelled TSC by topographic position for the entire grassland landscape on 14 September 2014.

classified as low, medium-low, medium-high, and high TSC according to landscape-wide average summit, mid-slope and toe-slope data are given in Table 4. Table 4 demonstrates the proportion of the AOI within each of these classes, based on the three distinct metrics for identification of grassland structure. Based on the relationship between plant height and TSC, low structure would account for $4.5 \%$ of the grassland landscape, and based on average TSC at summits, low structure would account for $2.8 \%$ of the landscape, for a difference of 519 ha.

Figures 3 and 4 depict maps of structure classes based on the TSC-Height and TSC-Topo models, respectively. There is a high degree of similarity between the two maps, with low structure areas mapped in Figure 3 also mapped in Figure 4.

\section{Discussion}

Both height and topographic position classifications indicated TSC for most of the landscape (between 85$87 \%$ ) was medium-high or high. The proportion of the AOI considered low was $4.5 \%$ based on height and $2.8 \%$ based on topography (Table 4). A greater proportion of the landscape was low using the TSC-Height model because a low threshold of $9 \mathrm{~cm}$ corresponded to 2014 $\mathrm{kg} / \mathrm{ha}$. The TSC-Topo model corresponded, on the other hand, to $1493 \mathrm{~kg} / \mathrm{ha}$ (Table 4). It is important to note that TSC needed to be modelled for the entire landscape to make these determinations. Extrapolation of the field estimates of plant height at the 48 non-summit locations only, meant $33 \%$ of the landscape would have been classified as low (Figure 1).

Our integrative approach that includes Landsat, DEM and field data provides a framework for field data extrapolation and adaptive management. Livestock 


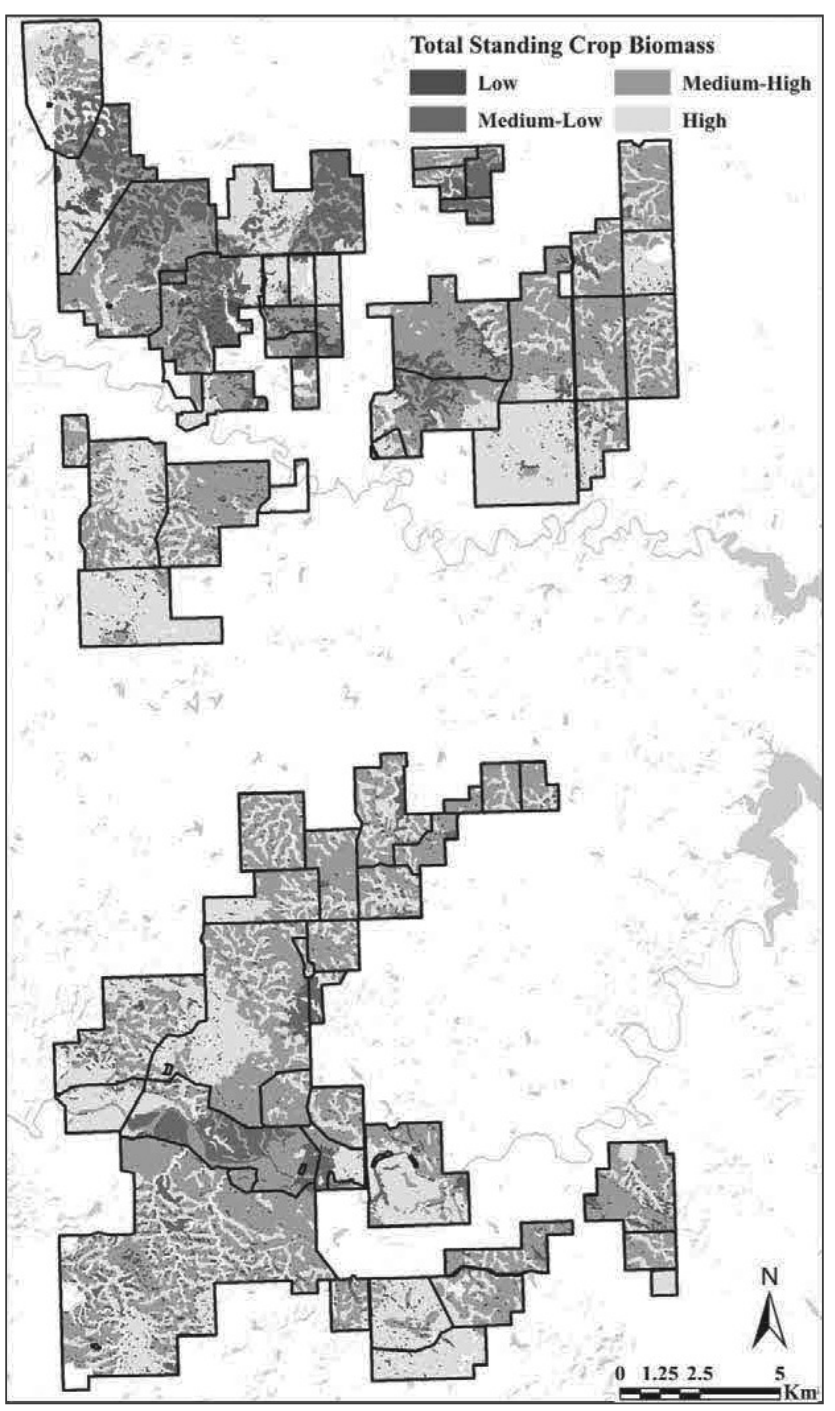

Figure 3 Proportion of landscape that was high, mediumhigh, medium-low, and low structure in September 2014 according to the TSC-height model thresholds.

need to graze grasslands each year, regardless of conditions, and management thresholds should be adaptable (Hunt et al. 2003; Schellberg et al. 2008). Repeated images and model runs would show how the landscape changes as a result of management and climate. Topographic variation in species, production, soil, canopy height, leaf area, and spectra at field sites over time (Phillips et al. 2012; Phillips 2014) in the United States and New Zealand hill country (Dodd et al. 2004; Leathwick \& Rogers 1996; Radcliffe 1982; Vartha et al. 1982) can guide managers to areas of overor under-utilised pasture and increase understanding of management effects on environment.

Costs associated with this framework will vary with the size and spatial variation of the landscape

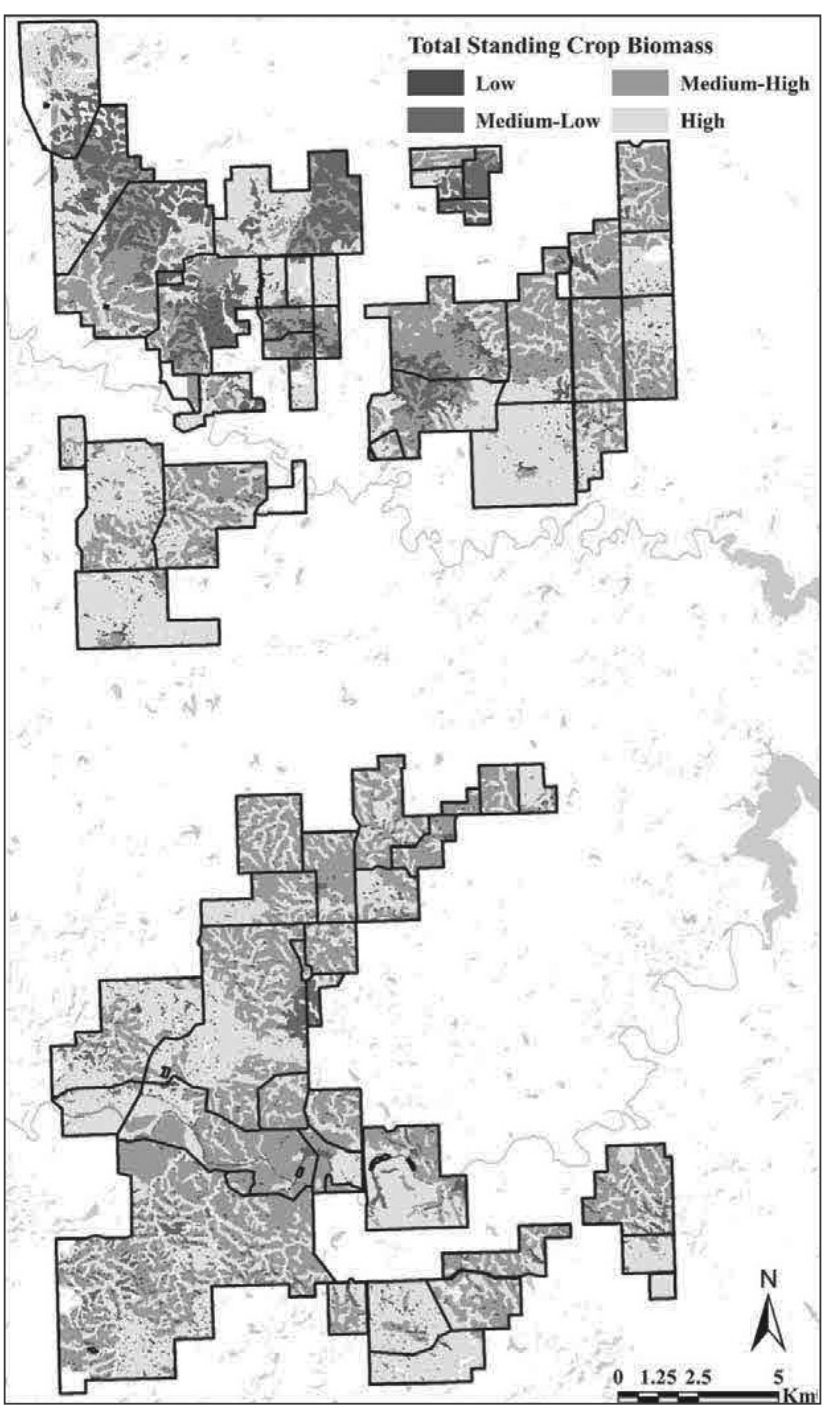

Figure 4 Proportion of landscape that was high, mediumhigh, medium-low, and low structure in September 2014 according to the TSC-Topo model thresholds.

and the assessment/monitoring goals. Initial set up requirements are detailed in Phillips et al. (2012); this is where the bulk of the costs are incurred. Spatial data are freely available online and processing is automated, so after initial set-up, regular assessment costs could be $<$ United States $\$ 1 / \mathrm{ha}$. This cost is an order of magnitude lower than costs associated with collection and processing of hyperspectral aerial data.

Results indicate this framework may be useful for (1) targeting pasture areas under- or over-utilised by livestock and (2) extrapolating field vegetation data in a spatially explicit manner. Relative TSC differences in summit, midslope, and toe-slope positions can serve as benchmarks that, when joined with field data, provide natural indicators of variables associated with grassland structure. 


\section{Conclusions}

Seasonal and annual changes in grassland canopy attributes require an assessment framework that can be flexible enough to account for variation in primary production. The spatially-integrated framework presented here is based on the premise that relative differences in summits, mid-slopes, and toe-slopes can provide meaningful benchmarks for managing seasonal variation in the whole-farm resource in hill-country landscapes at minimal expense.

\section{ACKNOWLEDGEMENTS}

The authors gratefully acknowledge Allen Will, Dan Svingen, Dennis Neitzke, and Karen Dunlap. We sincerely thank Reddy Pullanagari, Errol Thorn, and anonymous reviewers for their comments. This work was supported by USFS agreement 15-CS-11011800-014 and New Zealand Ecosystems and Global Change Fund.

\section{REFERENCES}

Beeri, O.; Phillips, R.; Hendrickson, J.; Frank, A.B.; Kronberg, S. 2007. Estimating Forage Quantity and Quality Using Aerial Hyperspectral Imagery for Northern Mixed-Grass Prairie. Remote Sensing of Environment 110: 216-225.

Chen, J.M. 1996. Canopy Architecture and Remote Sensing of the Fraction of Photosynthetically Active Radiation Absorbed by Boreal Conifer Forests. IEEE Transactions on Geoscience and Remote Sensing 34: 1353-1368.

Dalton, D.C.; Ackerley, L.R. 1974. Performance of Sheep on New Zealand Hill Country. New Zealand Journal of Agricultural Research 17: 279-282. doi: 10.1080/00288233.1974.10430555.

Dodd, M.B.; Barker, D.J.; Wedderburn, M.E. 2004. Plant Diversity Effects on Herbage Production and Compositional Changes in New Zealand Hill Country Pastures. Grass and Forage Science 59: 29-40.

Haboudane, D.; Miller, J.R.; Pattey, E.; Zarco-Tejada, P.J.; Strachen, I.B. 2004. Hyperspectral Vegetation Indices and Novel Algorithms for Predicting Green Lai of Crop Canopies: Modeling and Validation in the Context of Precision Agriculture. Remote Sensing of Environment 90: 337-352.

Hunt, R.E., Jr.; Everitt, J.H.; Ritchie, J.C.; Moran, M.S.; Booth, D.T.; Anderson, G.L.; Clark, P.E.; Seyfried, M.S. 2003. Applications and Research Using Remote Sensing for Rangeland Management. Photogrammetric Engineering \& Remote Sensing 69: 675-693.

Leathwick, J.R.; Rogers, G.M. 1996. Modelling Relationships between Environment and Canopy Composition in Secondary Vegetation in Central North Island, New Zealand. New Zealand Journal of Ecology 20: 147-161.
Phillips, R.L.; Beeri, O.; Liebig, M. 2006. Landscape Estimation of Canopy C:N Ratios under Variable Drought Stress in Northern Great Plains Rangelands. Journal of Geophysical Research 111: G02015. doi:10.1029/2005JG000135.

Phillips, R.L.; Ngugi, M.K.; Hendrickson, J.; Smith, A.; West, M. 2012. Mixed Grass Prairie Canopy Structure and Spectral Reflectances Varies with Topographic Position Environmental Management 50: 914-928.

Phillips, R.L.; West, M.; Saliendra, N.; Rundquist, B.; Pool, D. 2013. Prediction of Senescent Rangeland Canopy Structural Attributes with Airborne Hyperspectral Imagery. GIScience \& Remote Sensing 50: 133-153. doi: 10.1080/15481603.2013.793469.

Phillips, R.L. 2014. Mapping Grassland Structure at the Grand River National Grassland, South Dakota. pp. 174. Bismarck: U.S. Forest Service.

Pullanagari, R.; Dynes, R.; King, W.; Yule, I.; Thulin, S.; Knox, N.; Ramoelo, A.; Michalk, D.; Millar, G.; Badgery, W. 2013. Remote Sensing of Pasture Quality. pp. 633-638. In: Revitalising Grasslands to Sustain our Communities: Proceedings of the 22nd International Grassland Congress, Sydney, Australia.

Radcliffe, J.E. 1982. Effects of Aspect and Topography on Pasture Production in Hill Country. New Zealand Journal of Agricultural Research 25: 485-496. doi: 10.1080/00288233.1982.10425211.

Robel, R.J.; Briggs, J.N.; Dayton, A.D.; Hulbert, L.C. 1969. Relationships between Visual Obstruction Measurements and Weight of Grassland Vegetation. Journal of Range Management 23: 296-297.

Schellberg, J.; Hill, M.; Gerhards, R.; Rothmund, M.; Braun, M. 2008. Precision Agriculture on Grassland: Applications, Perspectives and Constraints. European Journal of Agronomy 29: 59-71.

Sjursen, P. 2009. Grand River National Grassland Robel Pole Inventory. U.S. Forest Service, Bismarck.

Svingen, D. 2009. Grassland Bird Managment on Public Lands in the United States: An Example From the Northern Great Plains. pp. 590-593. In: Proceedings of the Fourth International Partners in Flight Conference: Tundra to Tropics.

Uresk, D.W.; Benzon, T.A. 2007. Monitoring with a Modified Robel Pole on Meadows in the Central Black Hills of South Dakota. Western North American Naturalist 67: 46-50.

Uresk, D.W.; Juntti, T.M. 2008. Monitoring Idaho Fescue Grasslands in the Big Horn Mountains, Wyoming, with a Modified Robel Pole. Western North American Naturalist 68: 1-7.

USGS. 2014. Landsat Missions-Faq. landsat.usgs.gov/ band_designations_landsat_satellites.php Accessed: 10/06/2015 
USGS. 2015. Landsat 8 Data Users Handbook. LSDS-1574Congress:1-98. Retrieved October 20, 2015 (https://landsat.usgs.gov/documents/ Landsat8DataUsersHandbook.pdf).

Vartha, E.W.; Archie, W.J.; Archer, A.C.; Hoglund, J.H.; Macmillan, B.H. 1982. Management of Grassland on the Sunny Aspect of North Canterbury Dry Hill Country: Environment and Quantity and Quality of Herbage. New Zealand Journal of Agricultural Research 25: 475-483. doi: 10.1080/00288233.1982.10425210.
Vermiere, L.T.; Gillen, R.L. 2001. Estimating Herbage Standing Crop with Visual Obstruction in Tallgrass Prairie. Journal of Range Management 54: 57-60.

Vermiere, L.T.; Ganguli, A.C.; Gillen, R.L. 2002. A Robust Model for Estimating Standing Crop across Vegetation Types. Journal of Range Management 55: 494-497.

Washington-Allen, R.A.; West, N.E.; Ramsey, R.D.; Efroymson, R.A. 2006. A Protocol for Retrospective Remote Sensing-Based Ecological Monitoring of Rangelands. Rangeland Ecology \& Management 59: 19-29. 
